\title{
WIND TUNNEL CALIBRATION, CORRECTIONS AND EXPERIMENTAL VALIDATION FOR FIXED-WING MICRO AIR VEHICLES MEASUREMENTS
}

\author{
Ahmed ABOELEZZ ${ }^{1}{ }^{*}$, Yunes ELQUDSI ${ }^{2}$, Mostafa HASSANALIAN ${ }^{3}$, Ahmed DESOKI $^{2}$ \\ ${ }^{1}$ Institute of Aviation Engineering \& Technology, Cairo, Egypt \\ ${ }^{2}$ Department of Aerospace Engineering, Cairo University, Cairo, Egypt \\ ${ }^{3}$ Department of Mechanical Engineering, New Mexico Tech, Socorro, NM 87801, USA
}

Received 19 December 2019; accepted 21 January 2020

\begin{abstract}
The increase in the number of Unmanned Aerial Vehicles (UAVs) and Micro Air Vehicles (MAVs), which are used in a variety of applications has led to a surge in low Reynolds number aerodynamics research. Flow around fixedwing MAVs has an unusual behavior due to its low aspect ratio and operates at low Reynolds number, which demanded to upgrade the used wind tunnel for this study. This upgrade enables measuring the small aerodynamics forces and moment of fixed-wing MAVs. The wind tunnel used in this work is upgraded with a state of art data acquisition system to deal with the different sensors signals in the wind tunnel. For accurate measurements, the sting balance, angle sensor, and airspeed sensor are calibrated. For validation purposes, an experiment is made on a low aspect ratio flat plate wing at low Reynolds number, and the measured data are corrected and compared with published results. The procedure presented in this paper for the first time gave a detailed and complete guide for upgrading and calibrating old wind tunnel, all the required corrections to correct the measured data was presented, the turbulence level correction new technique presented in this paper could be used to estimate the flow turbulence effect on the measured data and correct the measured data against published data.
\end{abstract}

Keywords: wind tunnel, sting balance, calibration, uncertainty analysis, low aspect ratio, low Reynolds number.

\section{Introduction}

Several computational and experimental have attempted to compute MAV's aerodynamic forces and moments (Hassanalian \& Abdelkefi, 2017; Hassanalian, Khaki, \& Khosrawi, 2015). The simple Vortex Lattice Method was used by Stewart et al. (2007) and Hrad (2010) for aerodynamic analysis of the fixed-wing MAVs; however, these computational studies showed a low accuracy compared to experimental results. Rezaei and Taha (2017) utilized Computational Fluid Dynamics (CFD) techniques to investigate the unsteady aerodynamic response of a pitching NACA 0012 airfoil. In this study, the solution was validated versus wind tunnel testing. Mueller (2000) used an iterative design process to generate several conceptual designs and the most promising design was fabricated and tested in a wind tunnel. Experimental results were used to further refine the design. Torres and Mueller (2000) presented a detailed design procedure for MAVs based on wind tunnel data. A complete study for one MAV with an inverse Zimmermann platform was conducted in this study. In the experiment, an investigation was carried out to study (i) aerodynamic characteristics of the vehicle in the range of expected incidence and sideslip angles during the flight, (ii) the propeller effect on the aerodynamic data, and (iii) control surface effectiveness with additional incidence. Ohanian et al. (2012) used a wind tunnel to compare morphing control surfaces designs employing piezoelectric Macro Fiber Composite (MFC) actuators with servo-actuated control surfaces.

Lee and Gerontakos (2004) applied different techniques, such as surface pressure measurements and hotfilm measurements to measure the generated forces by an oscillating airfoil in a wind tunnel. Boutemedjet et al. (2004) used a sting balance that is an elastic structure to measure aerodynamic loads in a wind tunnel. The sting balance is generally classified based on the measured component and its location in the wind tunnel. In this study, a six-component sting balance was used to measure the

${ }^{*}$ Corresponding author. E-mail: ahmed.helmy.3zz@gmail.com

This is an Open Access article distributed under the terms of the Creative Commons Attribution License (https://creativecommons.org/licenses/by/4.0/), which permits unrestricted use, distribution, and reproduction in any medium, provided the original author and source are credited. 
momentum components and the sting balance was calibrated by a calibration rig before the wind tunnel measurements. Dickinson et al. (1999) and Nakata et al. (2011) used force sensors to measure lift and drag on a rotating insect wing. Traub (2018) presented the design of a lowcost wind tunnel balance but did not discuss the calibration technique. In this study, a validation experiment was conducted by comparing the measured data for slender delta wings against published data. Liu et al. (2015), investigated the interaction effect of different components on a five-component sting balance. In this work, a simple calibration was presented, and the sting balance was evaluated with designed experimental setups and evaluation procedures.

This paper describes the upgrading and calibration of an educational wind tunnel for a fixed-wing MAV aerodynamic loads measurements. The literature review indicates the importance of wind tunnel testing for aerodynamic analysis of the fixed-wing MAVs. Therefore, in this study, the applied wind tunnel for aerodynamic analysis was upgraded with a state of art data acquisition system to deal with the different sensors signals. The wind tunnel used in this study has as a sting balance (the sensor used to measure forces and moments for models in wind tunnel); hence, it needs to be calibrated. In this work, the sting balance is first calibrated using the described in Boyle (1988), Erm and Ferrarotto (2009) and Ulbrich and Gisler (2013). Then, uncertainty analysis and validation experiments are conducted to evaluate the calibrated wind tunnel data. Finally, wind tunnel corrections are applied to the validation experiment to eliminate the wind tunnel effect on measurements. The work presented in this paper was used to experimentally investigate the aerodynamics performance of the BlueBird MAV (Aboelezz et al., 2019).

\section{Experimental methodology}

\subsection{Wind tunnel characteristics}

To measure the aerodynamic loads of a fixed-wing MAV, an open-circuit subsonic wind tunnel is used. The tunnel entrance is fitted with a honeycomb flow straightener and turbulence reducing screens. The wind tunnel is driven by a $10 \mathrm{HP}$ motor that can generate a maximum speed of 30 $\mathrm{m} / \mathrm{s}$ with a turbulence intensity of $2 \%$, in the $0.47 \times 0.47 \times 1$ $\mathrm{m}$ test section volume. The used wind tunnel is equipped with five components force balance, such as axial $(4.5 \mathrm{~kg}$ Max.), normal (11 kg Max.) and side forces (4.5 kg Max.) in addition to pitching (55.4 m.kg Max.) and yawing moments (55.4 m.kg Max.) (Aerolab user's manual). In the current research, the normal force, the axial force and the pitching moment component are used.

\subsection{Wind tunnel upgrade}

Upgrading the wind tunnel will include a new positioning system using a servo motor to enable fast and automatic angle of attack change. A differential pressure sensor "Sensirion model SDP1000, $500 \mathrm{~Pa}$ range" is used to measure the pressure difference. The static pressure ring has four holes at the exact beginning walls of the test section that is used for measuring the static pressure. This static pressure will be used for pressure and wind speed measurements inside the tunnel test section. A Uxcell Single Linear Electric Carbon Rotary Potentiometer 250K Ohm is applied as an angle of attack sensor. National Instrument (NI) data acquisition (DAQs) will deal with the different signals from the different sensors. The NI 9237 data acquisition card is chosen since it contains the entire needed signal conditioning circuits in addition to the great flexibility of the accompanying LabView software. The DAQ card specifications are included in Table 1.

Table 1. DAQ card specifications used in this study

\begin{tabular}{|l|c|}
\hline \multicolumn{1}{|c|}{ DAQ Specification } & Value \\
\hline Channels number & 4 channels \\
\hline Sampling rate & $50 \mathrm{kS} / \mathrm{s}$ per channel simultaneous \\
\hline Input range & $\pm 25 \mathrm{mV} / \mathrm{V}$ \\
\hline Resolution & 24 -bit \\
\hline Bridge & $\begin{array}{c}\text { Programmable half- and full-bridge } \\
\text { completion }\end{array}$ \\
\hline
\end{tabular}

The sting balance has a strain gage bridge for each component. Each bridge has four wires going out from the sting balance, two for excitation volt and two for the output signals; by wiring these wires in the DAQ card, the output signals from the sting balance are processed.

\section{Calibrating the upgraded measuring system}

The calibration of the upgraded system is explained in this section. The calibration includes the sting balance, angle of attack and airspeed measurements.

\subsection{Sting balance calibration}

Due to the sting balance flexibility, if a pure load or moment is applied in the sting balance, it will give output signals in all three components. Therefore, the output signal in one direction would be a combination of the applied forces and moments. For sting balance, it is possible to assume that the measured forces and moments are linear with respect to the applied forces. The measured forces $(N$ : normal force, and $A$ : axial force) and moments ( $M$ : pitching moment) are given by the following equations (Boyle, 1988; Erm \& Ferrarotto, 2009).

$$
\begin{aligned}
& N_{R}=K_{11} N_{B}+K_{12} A_{B}+K_{13} M_{B} ; \\
& A_{R}=K_{21} N_{B}+K_{22} A_{B}+K_{23} M_{B} ; \\
& M_{R}=K_{31} N_{B}+K_{32} A_{B}+K_{33} M_{B} .
\end{aligned}
$$

The subscripts $R$ and $B$ stand for the measured and applied loads, respectively. $K_{i j}$ represents the linear slope between the applied load and the output signal, for example, $K_{11}=\partial N_{R} / \partial N_{B}$, where 1 for $N, 2$ for $A$ and 3 for $M$. The general form in matrix notation is given by: 


$$
\left\{F_{R}\right\}=K\left\{F_{B}\right\} \text {. }
$$

The sting balance will be removed from the wind tunnel and installed in a calibration test rig that is shown in Figure 1(a). The test rig enables fixation of the sting balance with any orientation and the rig itself is fixed to four adjustable legs to ensure leveling the rig. To obtain the calibration coefficients, $K_{i j}$, a pure load will be applied to the sting balance and the output signals will be plotted versus the applied loads. The loads will be applied to the sting balance using weights and holder shown in Figure 1(b).

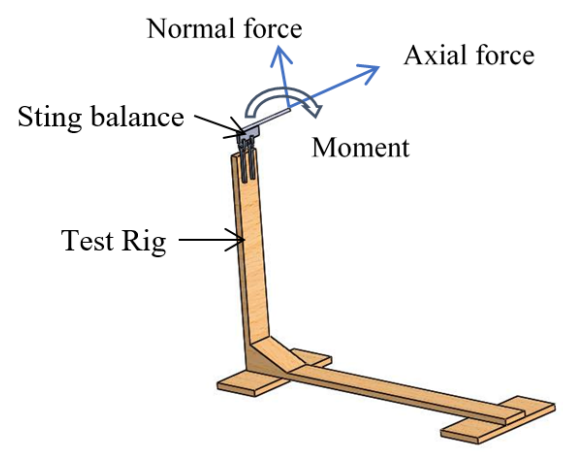

(a)

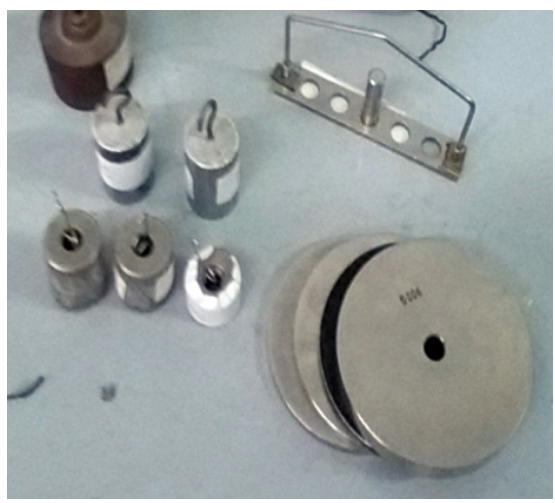

(b)

Figure 1. Views of (a) calibration test rig and (b) weights and holder used in the calibration

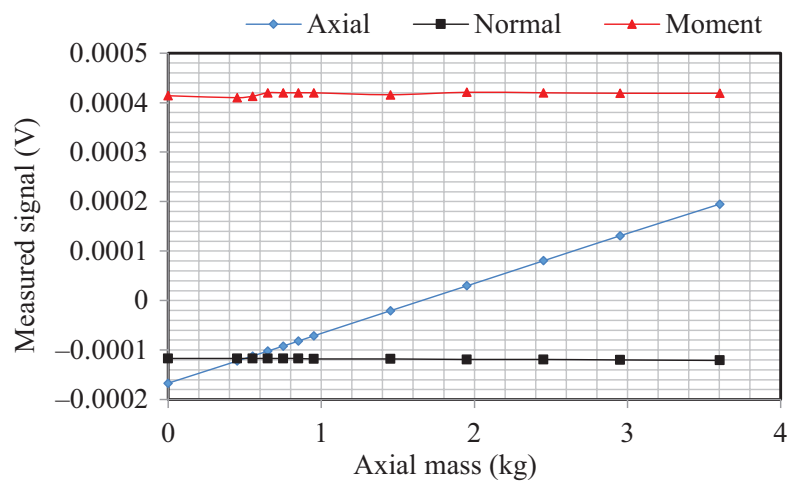

Figure 2. Axial component calibration

\subsection{Axial load calibration}

To measure $K$ matrix coefficients in the axial direction, the sting balance is fixed on the calibration rig while ensuring the axial direction of the sting balance is vertical. A pure axial load is applied (in the gravity direction) using weights and the weights holder on the sting balance leading edge. The output voltage for the three signal components (Normal, Axial, and Moment) are plotted as a function of the applied load as shown in Figure 2.

\subsection{Locating the moment center}

The sting balance moment center is the reference point for moment measurement. A calibration bar shown in Figure 3(a) is installed in the sting balance shown in Figure 3(b). The slots in the bar are used to hold the weight holder. This calibration bar is also needed for the normal force and pitching moment calibration. To locate the moment center, a $500 \mathrm{gm}$ constant load is applied at different locations (slots) in the calibration bar using the weight holder. The moment output signal is plotted versus the location. The moment center is the location where the moment signal is zero as shown in Figure 4. The moment center location could be predicted at $7.6 \mathrm{~cm}$ from the leading edge of the calibration bar and $2.6 \mathrm{~cm}$ from the sting balance leading-edge including the calibration bar weight (See Figure 5). The moment center experiment is repeated three times and the uncertainty bound for the location is $1 \mathrm{~mm}$.

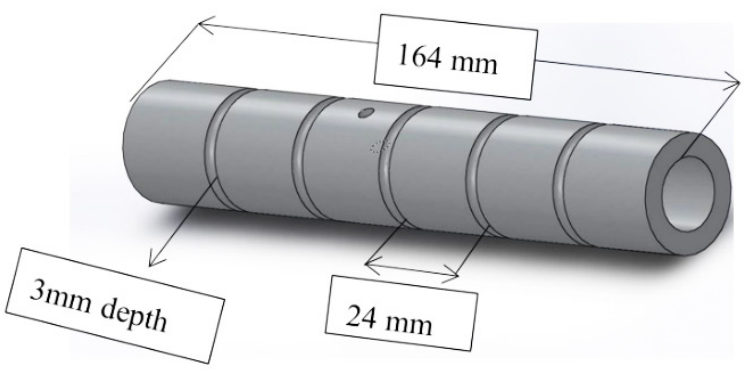

(a)

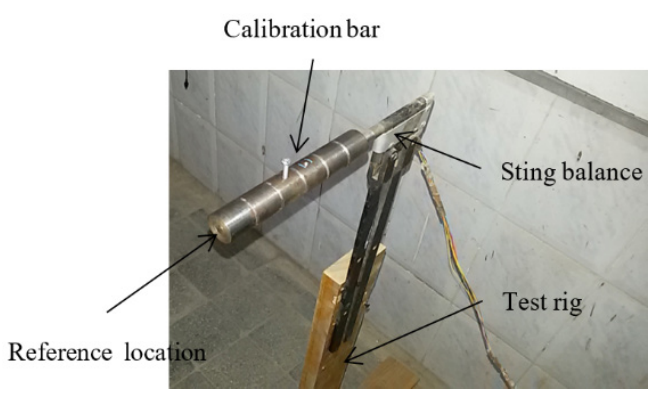

(b)

Figure 3. Views of (a) calibration bar and (b) calibration bar on the sting balance 


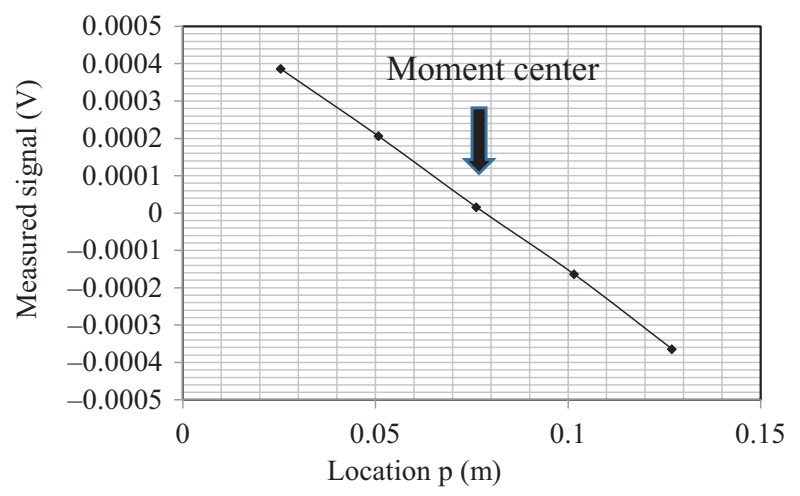

Figure 4. Views of moment center location in sting balance

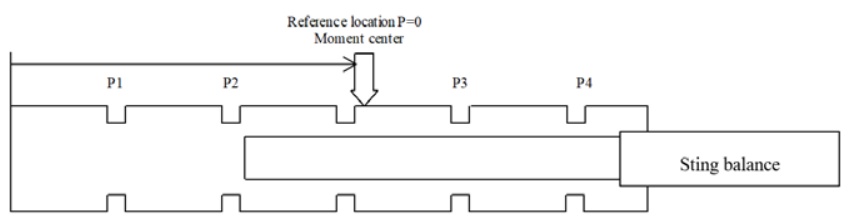

Figure 5. Different locations on the calibration bar and the moment center location

\subsection{Normal load calibration}

To calibrate the normal force component, a pure normal load is applied at the moment center as shown in Figure 6(a). This pure normal force load affects the different sting balance components. By plotting the output signal from the sting balance versus the applied loads as shown in Figure 6(b), the $K$ coefficients in the normal direction can be calculated. From slopes in Figure 6(b), the coefficients $K_{11}$, $K_{22}$, and $K_{31}$ are equal to $6.8611 \times 10^{-5},-1.1996 \times 10^{-6}$, and $-5.8572 \times 10^{-6} \mathrm{volt} / \mathrm{kg}$, respectively.

\subsection{Pitching moment calibration}

For the pitching moment calibration component, an alternative technique is needed because a pure moment cannot be applied. Therefore, a loaded schedule at different positions in the calibration bar is employed. The moment calibration component $K_{33}$ (the slope of applied moment versus the output moment signal) is expressed as follows:

$$
\begin{gathered}
K_{33}=\frac{\partial M_{R}}{\partial M_{B}}=\frac{1}{\partial M_{B} / \partial M_{R}} ; \\
\frac{\partial M_{B}}{\partial M_{R}}=\frac{\partial N_{B} \times \partial x}{\partial M_{R}}=\frac{\partial x}{\frac{\partial M_{R}}{\partial N_{B}}} .
\end{gathered}
$$

At each location in the calibration bar, the moment calibration component can be calculated. In Figures 7(a)$7(\mathrm{c})$, the axial, normal and moment components are measured and plotted for the different locations. The normal and axial component values change slightly with the location as seen in Figures 7(a) and 7(b) and this is proved because the slope of curves almost does not change. Figure 7(c) indicates that the moment readout component depends on the force location and weight value. Moreover, it shows that the positions before the moment center give positive slopes and the positions after the moment center give negative slopes.

The values of $K_{13}, K_{23}$, and $K_{33}$ for the moment components are determined from Figures $7(\mathrm{a})-7(\mathrm{c})$ that are equal to $5.4516 \times 10^{-5},-3.1904 \times 10^{-5}$, and $2.1415 \times 10^{-3}$, respectively.

\subsection{The angle of attack calibration}

The potentiometer that is used for measuring the angle of attack inside the wind tunnel, is also calibrated. Dial Angle Finder with $0.5^{\circ}$ uncertainty (See Figure $8(\mathrm{a})$ ) is applied to calibrate the angle of attack. The output signal from the potentiometer is measured and plotted versus the measured angle of attack, and the results are shown in Figure 8(b).

\subsection{Airspeed calibration}

A differential pressure sensor is used to determine the airspeed in the wind tunnel. The sensor measures the pressure difference between the static pressure $\left(P_{s}\right)$ at the

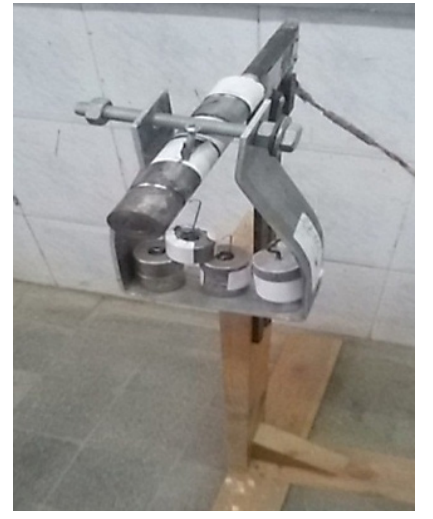

(a)

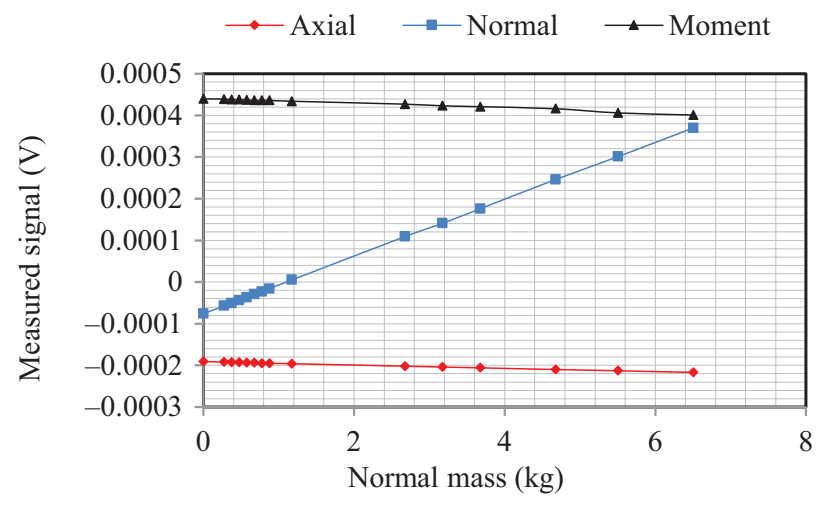

(b)

Figure 6. Views of (a) normal component calibration and (b) measured output signal from the sting balance versus the applied loads 


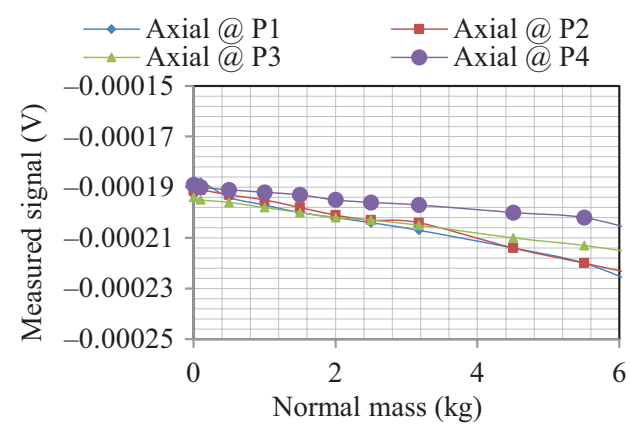

(a)

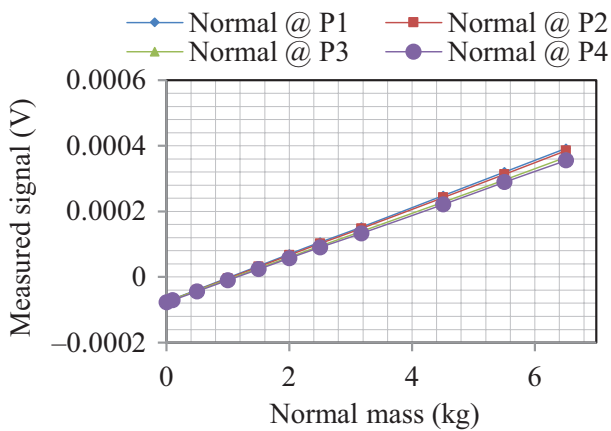

(b)

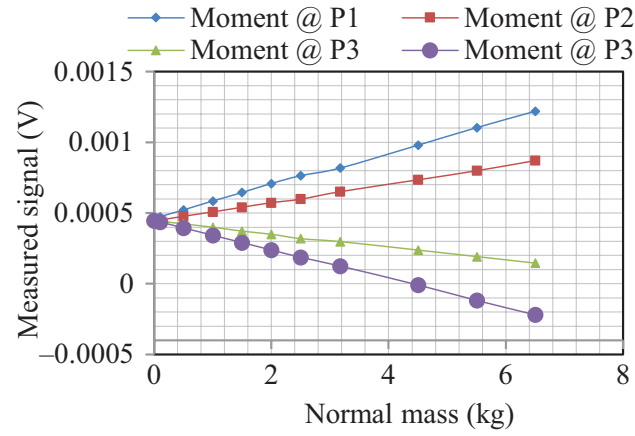

(c)

Figure 7. Views of (a) axial signals, (b) normal signals, and (c) moment signals versus normal load for different locations

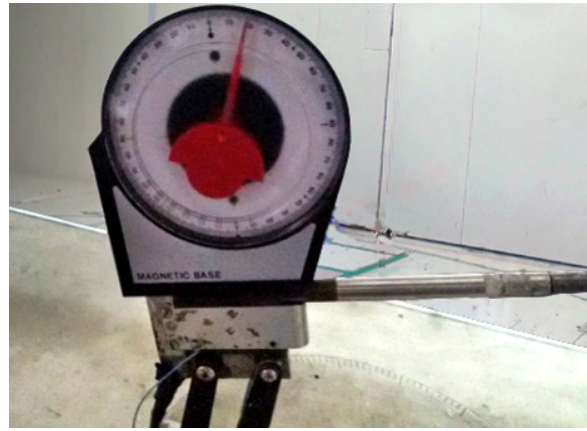

(a)

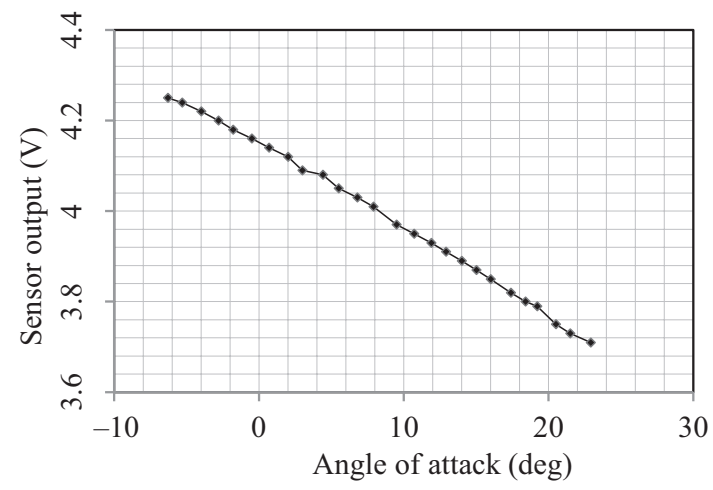

(b)

Figure 8. Views of (a) the angle of attack calibration, and (b) angle of attack calibration signal

beginning of the test section and the atmospheric pressure $P_{a t m}$. It is assumed that the total pressure is equal to atmospheric pressure. Based on the Bernoulli equation, the wind velocity, $V$, can be calculated as:

$$
V=\sqrt{2\left(P_{a t m}-P_{s}\right) / \rho} \text {. }
$$

As $\left(P_{a t m}-P_{s}\right)$ is the output from the pressure sensor:

$$
V=\text { sensoroutput } \times \sqrt{\frac{2}{\rho}} \text {. }
$$

A handheld commercial hotwire anemometer with $1.25 \mathrm{~m} / \mathrm{s}$ uncertainty is used to measure the airspeed and plot the relationship between the sensor outputs against the airspeed. The result is shown in Figure 9. Also, the dynamic pressure is equal to the output of the pressure sensor based on Eq. (7).

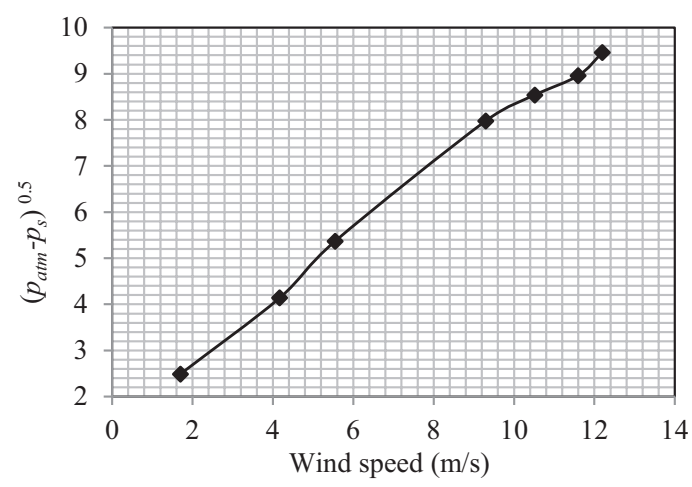

Figure 9. Wind speed calibration 


\section{Uncertainty analysis}

The quality and reliability of the values obtained from experiments are important. In this study, an uncertainty analysis is carried out to accept and deal satisfactorily with the measured values. There are many sources for the uncertainty of the obtained values including the measurement instruments, the calibration accuracy, and the statistical analysis of the actual measured values. For example, to calculate the statistical uncertainty that comes from the sting balance, the lift component $(L)$ is measured six times for different angles of attack $\left(\alpha=-5^{\circ}\right.$ to $\left.20^{\circ}\right)$, as shown in Table 2.

The uncertainty $U_{j}$ is defined as follows:

$$
U_{j}=\frac{\sigma}{\sqrt{N}},
$$

where $\sigma$ and $N$ are a standard deviation and the total number of trials, respectively. In order to estimate the uncertainty of the lift and drag forces, the sensitivity coefficients, $c_{j}$, should be calculated. These coefficients are equal to the change of the quantity of lift and drag coefficients $\left(C_{L}, C_{D}\right)$ divided by the changes of the influential factors $(L, D, \alpha, V, \ldots)$. For example, for $j=1$, we have:

$$
\begin{aligned}
& c_{1}=\frac{\partial C_{L}}{\partial L}=\frac{1}{q S}=0.7407 ; \\
& q=\frac{1}{2} \rho V^{2}=P_{a t m}-P_{s},
\end{aligned}
$$

where $S, q$, and $V$ are wing area, dynamic pressure, and wind speed, respectively.

The sources of uncertainty in measuring the aerodynamic forces are (1) uncertainty in measuring the dynamic pressure value because of the pressure sensor accuracy, (2) uncertainty of measuring the angle of attack due to the accuracy of the potentiometer that calibrated with the Dial Angle Finder, and (3) uncertainty in the sting balance reading associated with its accuracy. The dynamic pressure in the test section can be determined by measuring the pressure difference between the static pressure $\left(P_{s}\right)$ at the beginning of the test section and the atmospheric pressure $P_{a t m}$. A differential pressure sensor is used to measure the pressure difference between the static ring and the atmosphere, where the uncertainty of the pressure sensor according to its datasheet is $0.5 \%$ reading +1 digit. The sensitivity coefficients of $\partial C_{L} / \partial V$ and $\partial C_{D} / \partial V$ can be determined by plotting lift and drag coefficient versus wind speed at different angles of attack.
For the angle of attack $(\alpha)$, the standard uncertainty is equal to $(0.5) / 2$, where 0.5 is the worst uncertainty in measuring the angle of attack. The sensitivity coefficients for lift and drag forces are calculated by determining the slope of lift and drag coefficient versus angle of attack, $c_{j}=$ $\left(\partial C_{L}\right) / \partial \alpha$ and $c_{j}=\left(\partial C_{D}\right) / \partial \alpha$. The calibration uncertainty $U_{j}$ for sting balance measurements is equal to $0.006 \mathrm{~kg}$ (about $0.06 \mathrm{~N}$ ) which leads to 0.03 standard uncertainty. The sensitivity coefficient for the sting balance measurements is equal to 0.7407 .

After determining the different standard uncertainties, collective uncertainty, $u_{c}$, is calculated as:

$$
u_{c}=\sqrt{\sum_{j=1}^{n}\left|c_{j} u\left(x_{j}\right)\right|^{2}} .
$$

In order to determine the confidence of the computed uncertainty $U$, the effective degree of freedom $\beta_{\text {eff }}$ is calculated by Welch-Satterwaite formula as follow:

$$
\beta_{e f f}=\beta \frac{u_{c}{ }^{4}}{\sum_{j=1}^{n}\left|c_{j} u\left(x_{j}\right)\right|^{4}},
$$

where $\beta=$ (sample size -1$)$. The commonly chosen confidence interval in estimating certain parameters is $95 \%$ (Bentley, 2005). In this study, since the data are normally distributed, the standard deviation is equal to \pm 1.96 about the mean. For $95 \%$ confidence interval, the uncertainty of the measurements in this work is equal to the estimated overall uncertainty $\left(U_{T}\right)$, where $U_{T}=K \times u_{c}$ and $K$ is the coverage factor which is chosen as 1.96 for $95 \%$ confidence interval (Bentley, 2005). To summarize this section, there are three sources of uncertainty in the measurements including (1) the dynamic pressure, (2) the angle of attack, and (3) the forces and moment. Each of these sources has it is own uncertainty. These uncertainties can be determined from the sensor datasheet or based on the sensor calibration.

\section{Wind tunnel corrections including turbulence level effects on low Reynolds number}

The flow in the free stream is different from the flow in the wind tunnel. The walls of the tunnel affect the flow stream and the wind tunnel generally does not have the same distribution of flow properties in real cases (Pope \& Rae, 1984). As the flow goes down in the test section, the boundary layer on the tunnel walls increases that causes a reduction in the effective area in the test section. In the wind tunnel, the solid blockage is defined as the ra-

Table 2. Samples of the statistical analysis

\begin{tabular}{|c|c|c|c|c|c|c|c|}
\hline$\alpha$ & $L_{1}(\mathrm{~kg})$ & $L_{2}(\mathrm{~kg})$ & $L_{3}(\mathrm{~kg})$ & $L_{4}(\mathrm{~kg})$ & $L_{5}(\mathrm{~kg})$ & $L_{6}(\mathrm{~kg})$ & Average $L$ \\
\hline$-5^{\circ}$ & -0.0191 & -0.01499 & -0.01638 & -0.01503 & -0.01257 & -0.01866 & -0.01612 \\
\hline$-4.5^{\circ}$ & -0.0173 & -0.01366 & -0.01489 & -0.0137 & -0.01154 & -0.01691 & -0.01467 \\
\hline $19.5^{\circ}$ & 0.0988 & 0.09451 & 0.09631 & 0.09586 & 0.09588 & 0.09744 & 0.09646 \\
\hline $20^{\circ}$ & 0.1018 & 0.09769 & 0.09946 & 0.09910 & 0.09932 & 0.10046 & 0.09964 \\
\hline
\end{tabular}


tio between the test section and frontal area of the model. Based on (Pope \& Rae, 1984), for the model to tunnel area ratio higher than 0.10 , the solid blockage should be taken into consideration. The wake blockage is the effect of the model's generated wakes on the test section of the wind tunnels. Generally, for large wakes, its effect on measurements cannot be ignored especially for low aspect ratio wings in high angle of attacks. The wind tunnel streamlines curvature is different from the real flow, which affects the moment and lift coefficients, and also the angle of attack.

There are many methods for wind tunnel corrections, such as the method of images, panel methods, measured variable methods, and the chart method (Pope \& Rae, 1984). In this study, the measured variable method can be used for wind tunnel corrections, but it will require to add more sensors to the tunnel with extra modifications in the tunnel's walls. A simplified method has been presented in (Shindo, 1995) that does not require installing more sensors to modify the tunnel. The corrections can be calculated with the following equations (Shindo, 1995):

$$
\varepsilon=\frac{S}{D}\left\{C_{D}-C_{L}^{2}\left[\frac{1}{\pi A R}-\delta_{W} \frac{S}{D}\right]\right\}
$$

where $\varepsilon$ is the correction factor, $S$ is the wing area, $D$ is the tunnel cross-section area, $C_{D}$ and $C_{L}$ are the measured drag and lift coefficient, and $\delta_{W}$ is the boundary-correction factor that can be obtained from (Silverstein \& White, 1937). The corrected dynamic pressure $\left(q_{c}\right)$ is calculated as:

$$
q_{c}=q(1+\varepsilon)^{2} \text {. }
$$

This dynamic pressure is used for the corrected lift and drag coefficients $\left(C_{L c}\right.$ and $\left.C_{D c}\right)$. These two coefficients are used in the following equations:

$$
\begin{aligned}
& \alpha=\alpha_{c}+\delta_{W}\left(\frac{S}{D}\right) C_{L c} ; \\
& C_{D}=C_{D c}+\delta_{W}\left(\frac{S}{D}\right) C_{L c}^{2},
\end{aligned}
$$

where $\alpha$ is angle of attack.

With these corrections, the results will need one more additional correction for the wind tunnel turbulence level. Cheung and Melbourne (1980) conducted experiments on the cylinder for different blockage ratios and different
Reynolds number. In these experiments, they included the turbulence effects by adding grids in the entrance of the wind tunnel test section. They showed that the variation in grid size changes the turbulence level in the test section. They also concluded that the change in turbulence level requires a change in the wind tunnel correction, especially in low Reynolds number flow. Wang et al. (2014). investigated the turbulent intensity and Reynolds number effects on an airfoil at low Reynolds numbers (Wang et al., 2014). They indicated that the effect that occurs due to increasing the turbulence is the same as the effect of increasing the Reynolds number. The turbulence factor (TF) is calculated as:

$$
T F=R e_{e f f} / R e,
$$

where $R e$ is the Reynolds number and $R e_{\text {eff }}$ is the actual Reynolds number affecting the airfoil. In this study, it is assumed that the change in the Reynolds number will cause a change in the flow velocity in the incompressible low Reynolds number flow.

Cruz studied the turbulence intensities that fixedwing MAVs may experience when flying at low altitudes and speeds in two wind tunnel facilities using mesh grids (Cruz, 2012). In this study, he used three airfoils in 2D and $3 \mathrm{D}$ configurations. The TF was estimated by using his investigation on flat plate airfoils. These investigations were used to determine the effective Reynolds number. Then, the effective velocity was calculated from effective $R e$ to correct the effect of the wind tunnel turbulence level in calculation of the aerodynamic loads' coefficients.

\section{Validating the upgraded measuring system}

To validate the upgraded measurement system and the calibration of the sting balance, angle of attack, and airspeed sensors, an experiment is conducted on a low aspect ratio and low Reynolds number wing. The wing used in this validation experiment has the same geometry as the wing described in (Torres \& Mueller, 2004) (see Figure10(a)). The corrected measured data using the upgraded measuring system are then compared with the measurements reported by Torres and Mueller (2004). The studied flat plate wing installed in the wind tunnel is shown in Figure 10(b). This wing has an aspect ratio of 0.75 and a Reynolds number of $1 \times 10^{5}$. The angle of attack for this wing is changing from $5^{\circ}$ to $22^{\circ}$.

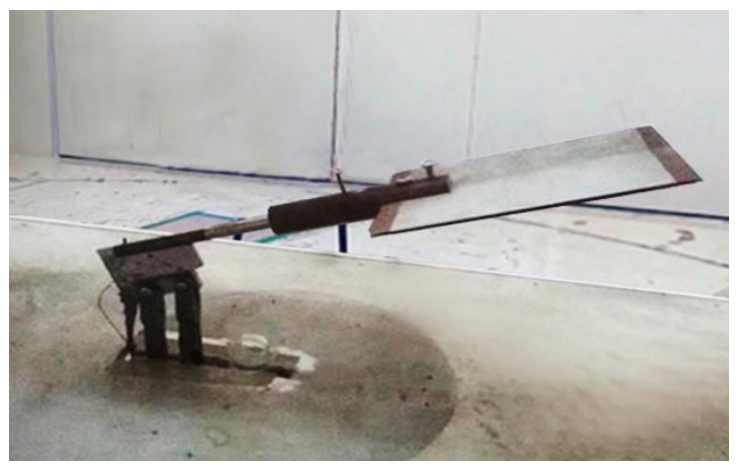

(b)

Figure 10. Views of (a) low aspect ratio flat plate wing, and (b) installed flat plate wing in the wind tunnel 


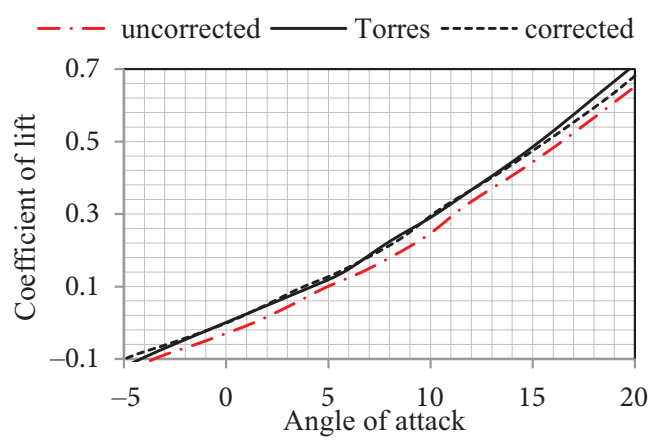

(a)

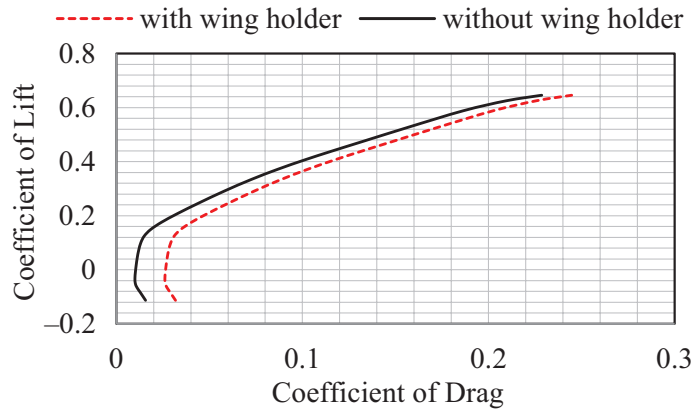

(b)

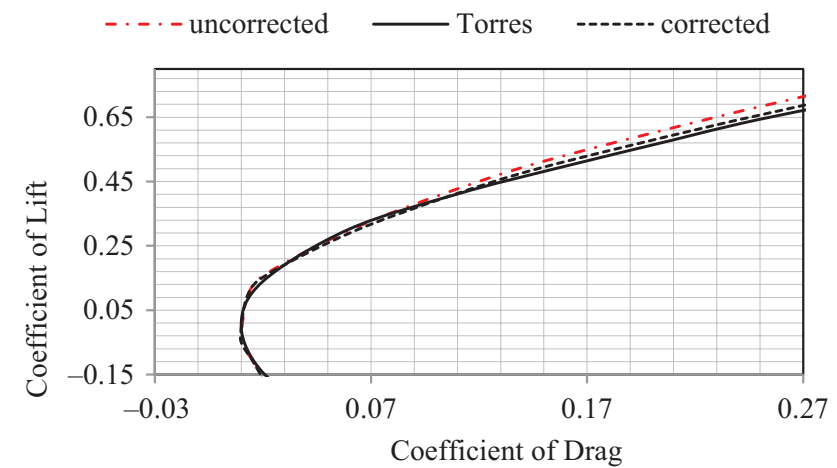

(c)

Figure 11. Views of (a) lift coefficient versus angle of attack, (b) drag polar with and without wing holder, and (c) lift coefficient versus drag coefficient at $R e=10^{5}$

In Figure 11(a), the measured lift coefficient in the experiment is compared with the results of the experiments conducted by Torres and Mueller (2004). In this study, to reduce the effects of hysteresis and to obtain the bounds for experimental uncertainty, the experiment is repeated for six times. The uncorrected curve has a flow angularity with about $1^{\circ}$ which causes the curve to move right and the blockage effect causes the curve to move up. As seen from the results, there is a maximum error of $4 \%$ between the uncorrected data and data obtained by Torres and $\mathrm{Mu}$ eller (2004).

To consider the drag added by the wing holder, the wing is removed from the wing holder and the drag polar is measured for the wing holder. This measurement is used to plot the drag polar with and without the wing holder as shown in Figure 11(b) for the mean coefficients of lift and drag. This correction is needed as it can affect the comparison with the experiment conducted by Torres and Mueller (2004).

Figure 11(c) indicates the comparison of the drag polar for the measurements in this study with the results published by (Torres \& Mueller, 2004). The maximum error value in uncorrected data is $6.2 \%$ compared to the Torres and Mueller data. This means that for a lift coefficient, the drag coefficient has a $6.2 \%$ higher value compared to the experimental results in Torres and Mueller (2004). This difference happens due to blockage and tunnel interference. As can be seen from Figure 11, the results can be improved by using wind tunnel corrections.
As shown in this paper, the upgraded system yields result in a good agreement with the experimental results obtained by Torres and Mueller with an uncertainty of 5\% for lift and drag coefficients. Allan et al. (2004) and Pass (1987) indicated that for a blockage ratio of less than 0.08 and a wingspan to tunnel-width ratio less than $75 \%$, the tunnel interference can be negligible. This assumption in this study is not valid because of low Reynolds number and low aspect ratio conditions. In this work, the results are corrected considering the solid blockage, wake blockage, streamline curvature and turbulence level corrections. The maximum corrections for lift and drag are about $8 \%$ and these corrections include $3.75 \%$ for turbulence correction as shown in Figure 12.

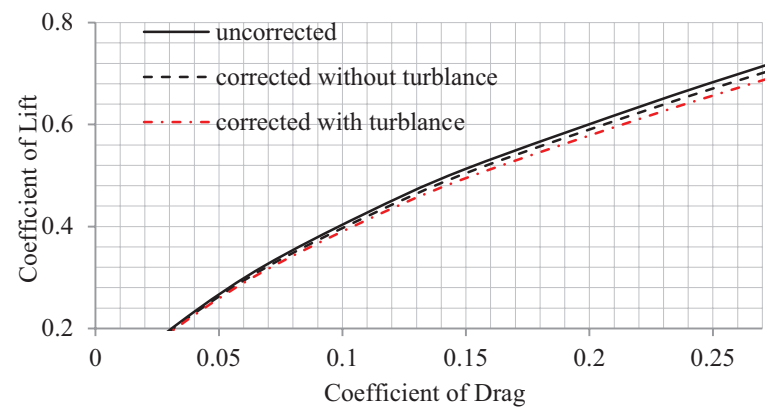

Figure 12. Lift coefficient versus drag coefficient at $R e=10^{5}$ (corrections effect on the measurements) Figure 12. Lift coefficient versus drag coefficient at $R e=10^{5}$ (corrections effect on the measurements) 


\section{Conclusions}

Wind tunnels with a large test section can measure the aerodynamics loads of larger aircraft models and flow with higher Reynolds numbers. However, smaller wind tunnels can be used for fixed-wing Micro air vehicles (MAVs) with low aspect ratios that are operating in low Reynolds numbers. In this study, a small wind tunnel has been upgraded with a data acquisition system, to measure the aerodynamic loads of a fixed-wing MAV. A test rig was designed and manufactured to calibrate the sting balance outside the wind tunnel. By using a calibration procedure, it was possible to extract the relation between the applied loads to the sting balance and the output signals from the DAQ. These relations were used to estimate the calibration coefficients of the sting balance. These coefficients convert electrical signals to forces and moment values that can be used in the wind tunnel measurements. The moment center location also was predicted to be at $7.6 \mathrm{~cm}$ from the leading edge of the calibration bar. The sting balance calibration results also indicated high linearity between the applied loads and the output signals. In this work, the angle of attack and airspeed sensor were also calibrated. To validate the upgraded measurement system and the calibration of the sting balance, angle of attack, and airspeed sensors, experiments were conducted on a wing with a low aspect ratio in a low Reynolds number. The measured data in this study were corrected to exclude the wind tunnel effects. The experimental results showed a very good agreement with the study carried out by Torres and Mueller. It was indicated that for the uncorrected data, the maximum error values for drag and lift are $6.2 \%$ and $4 \%$, respectively.

\section{Conflict of interest}

The authors declare that they have no conflict of interest.

\section{References}

Aboelezz, A., et al. (2019). Design, experimental investigation, and nonlinear flight dynamics with atmospheric disturbances of a fixed-wing micro air vehicle. Aerospace Science and Technology, (2019), 105636.

https://doi.org/10.1016/j.ast.2019.105636

AEROLAB LLC. (2019). Aerolab Educational Wind Tunnel (EWT) owner's manual. https://www.aerolab.com/products/ educational-wind-tunnel-ewt/

Allan, M. R., Badcock, K. J., Barakos, G. N., \& Richards, B. E. (2004). Wind-tunnel interference effects on a 70 delta wing. The Aeronautical Journal, 108(1088), 505-513. https://doi.org/10.1017/S0001924000000336

Bentley, J. P. (2005). Uncertainty in Measurement System: The ISO guide. National Measurement Institute, Sydney, Australia.

Boutemedjet, A., Samardžić, M., Ćurčić, D., Rajić, Z., \& Ocokoljić, G. (2018). Wind tunnel measurement of small values of rolling moment using six-component strain gauge balance. Measurement, 116, 438-450.

https://doi.org/10.1016/j.measurement.2017.11.043

Boyle, M. T. (1988, February). Low speed wind tunnel testing. In Fourth annual IEEE semiconductor thermal and temperature measurement symposium (pp. 31-39). San Diego, CA, USA. IEEE.
Cheung, C. K., \& Melbourne, W. H. (1980). Wind tunnel blockage effects on a circular cylinder in turbulent flows. In 7th Australasian Conference on Hydraulics and Fluid Mechanics 1980: Preprints of Papers (p. 127). Institution of Engineers, Australia.

Cruz, E. (2012). The effect of turbulence on micro air vehicle airfoils (PhD). Aerospace, Mechanical and Manufacturing Engineering, RMIT University.

Dickinson, M. H., Lehmann, F. O., \& Sane, S. P. (1999). Wing rotation and the aerodynamic basis of insect flight. Science, 284(5422), 1954-1960.

https://doi.org/10.1126/science.284.5422.1954

Erm, L. P., \& Ferrarotto, P. (2009). Development of a five-component strain-gauge balance for the DSTO water tunnel (No. DSTO-GD-0597). Defence science and technology organisation Victoria (Australia) air vehicles division.

Hassanalian, M., \& Abdelkefi, A. (2017). Classifications, applications, and design challenges of drones: A review. Progress in Aerospace Sciences, 91, 99-131.

https://doi.org/10.1016/j.paerosci.2017.04.003

Hassanalian, M., \& Abdelkefi, A. (2017). Conceptual design and analysis of separation flight for an unmaned air vehicle to five micro air vehicles. In 55th AIAA Aerospace Sciences Meeting (p. 0240). Grapevine, Texas.

https://doi.org/10.2514/6.2017-0240

Hassanalian, M., \& Abdelkefi, A. (2017). Design, manufacturing, and flight testing of a fixed wing micro air vehicle with Zimmerman planform. Meccanica, 52(6), 1265-1282.

https://doi.org/10.1007/s11012-016-0475-2

Hassanalian, M., Khaki, H., \& Khosravi, M. (2015). A new method for design of fixed wing micro air vehicle. Proceedings of the Institution of Mechanical Engineers, Part G: Journal of Aerospace Engineering, 229(5), 837-850. https://doi.org/10.1177/0954410014540621

Hassanalian, M., Rice, D., Johnstone, S., \& Abdelkefi, A. (2018). Performance analysis of fixed wing space drones in different solar system bodies. Acta Astronautica, 152, 27-48. https://doi.org/10.1016/j.actaastro.2018.07.018

Hrad, P. M. (2010). Conceptual design tool for fuel-cell powered micro air vehicles (No. AFIT/GAE/ENY/10-M12). Air force institute of Tech Wright-Patterson AFB OH graduate school of engineering and management.

Lee, T., \& Gerontakos, P. (2004). Investigation of flow over an oscillating airfoil. Journal of Fluid Mechanics, 512, 313-341. https://doi.org/10.1017/S0022112004009851

Liu, Z., Dong, L., Zhao, J., \& Yan, G. (2015). Components interaction effect evaluation of a small-capacity five-component internal balance system. Proceedings of the Institution of $\mathrm{Me}$ chanical Engineers, Part C: Journal of Mechanical Engineering Science, 229(1), 125-135.

https://doi.org/10.1177/0954406214531747

Mueller, T. J. (2000). Aerodynamic measurements at low raynolds numbers for fixed wing micro-air vehicles. Notre Dame university in dept of aerospace and mechanical engineering.

Nakata, T., Liu, H., Tanaka, Y., Nishihashi, N., Wang, X., \& Sato, A. (2011). Aerodynamics of a bio-inspired flexible flapping-wing micro air vehicle. Bioinspiration \& Biomimetics, 6(4), 045002. https://doi.org/10.1088/1748-3182/6/4/045002

Ohanian, O., Hickling, C., Stiltner, B., Karni, E., Kochersberger, K., Probst, T., ... \& Blain, A. (2012, April). Piezoelectric morphing versus servo-actuated MAV control surfaces. In 53rd AIAA/ASME/ASCE/AHS/ASC Structures, Structural Dynamics and Materials Conference 20th AIAA/ASME/AHS Adaptive Structures Conference 14th AIAA. Vancouver, British Columbia, Canada (p. 1512). https://doi.org/10.2514/6.2012-1512 
Pass, C. (1987, January). A wake blockage correction method for small subsonic wind tunnels. In 25th AIAA Aerospace Sciences Meeting. Delft, The Netherlands (p. 294).

https://doi.org/10.2514/6.1987-294

Pope, A., \& Rae, W. H. (1984). Low-speed wind tunnel testing. Wiley-Interscience.

Rezaei, A. S., \& Taha, H. E. (2019). Transition regime and its effects on the unsteady aerodynamic characteristics of a pitching airfoil. In AIAA Scitech 2019 Forum (p. 0302). San Diego, California. https://doi.org/10.2514/6.2019-0302

Shindo, S. (1995). Simplified tunnel correction method. Journal of Aircraft, 32(1), 210-213. https://doi.org/10.2514/3.46705

Silverstein, A., \& White, J. A. (1937). Wind-tunnel Interference with particular reference to off-center positions of the wing and to the downwash at the tail. Annual Report - National Advisory Committee for Aeronautics, Vol. 22.

Stewart, K., Wagener, J., Abate, G., \& Salichon, M. (2007). Design of the air force research laboratory micro aerial vehicle research configuration. In 45th AIAA Aerospace Sciences Meeting and Exhibit. Reno, Nevada (p. 667).

https://doi.org/10.2514/6.2007-667
Torres, G. E., \& Mueller, T. J. (2004). Low aspect ratio aerodynamics at low Reynolds numbers. AIAA Journal, 42(5), 865873. https://doi.org/10.2514/1.439

Torres, G., \& Mueller, T. J. (2000, July). Micro aerial vehicle development: design, components, fabrication, and flighttesting. In AUVSI Unmanned Systems 2000 Symposium and Exhibition. Japan (pp. 11-13).

Traub, L. W. (2018). Design of a low-cost rapid-prototyped windtunnel balance. Journal of Aircraft, 55(5), 2149-2153. https://doi.org/10.2514/1.C034982

Ulbrich, N., \& Gisler, R. (2013, January). A baseline load schedule for the manual calibration of a force balance. In 51st AIAA Aerospace Sciences Meeting including the New Horizons Forum and Aerospace Exposition (p. 1017). Grapevine (Dallas/Ft. Worth Region), Texas. https://doi.org/10.2514/6.2013-1017

Wang, S., Zhou, Y., Alam, M. M., \& Yang, H. (2014). Turbulent intensity and Reynolds number effects on an airfoil at low Reynolds numbers. Physics of Fluids, 26(11), 115107. https://doi.org/10.1063/1.4901969 